\title{
LÓGICA E RETÓRICA EM DIÁLOGO: POR UM ESTudo/Ensino da Língua PoRTuguesa COMO IDEAL DE COMPETÊNCIA PARA A CIDADANIA
}

\author{
A dialogue between logic and rhetoric: for a \\ study/teaching of the Portuguese language as an \\ ideal of citizenship competencies
}

\author{
Léia Cruz de Menezes* \\ Ramon Souza Capelle de Andrade ${ }^{* *}$
}

\begin{abstract}
RESUMO
O presente artigo tem por objetivo discutir as bases teóricas para um trabalho didático que possibilite aproximar o estudo/ ensino da língua portuguesa do ideal de competências para a cidadania. Neste sentido, postulamos a importância de um trabalho pedagógico interdisciplinar, no âmbito do qual a lógica e a retórica atuariam em relação de complementaridade. Enquanto a perspectiva da retórica (PERELMAN, 1958 [1996], 1977 [1993], 1989 [1997]) respalda o trabalho pedagógico com a organização linguística do texto-discurso para fins de estruturação de nossos pontos de vista acerca de como interpretamos o mundo, a perspectiva da lógica (PEIRCE, 1958) promove o apreço pela argumentação e explicitação daquilo que fundamenta nossos discursos. Essa relação de complementaridade entre lógica e retórica constitui a fundamentação teórica da Proposta, aprovada em Edital do MEC, de Educação Tutorial (PET) intitulada "Respeito à diversidade cultural: o papel da lógica e da retórica na constituição do Eu cidadão", da área de
\end{abstract}

* Professora Adjunta I da Universidade da Integração Internacional da Lusofonia Afro-Brasileira (Unilab), lotada na Área de Humanidades e Letras. Doutora em Linguística pela UFC.

** Professor Adjunto I da Universidade da Integração Internacional da Lusofonia Afro-Brasileira (Unilab), lotado na Área de Humanidades e Letras. Doutor em Filosofia pela UNICAMP. 
Humanidades e Letras da Universidade da Integração Internacional da Lusofonia Afro-Brasileira (UNILAB).

Palavras-chave: organização discursiva; retórica; lógica.

\begin{abstract}
This article discusses the theoretical basis for educational work that makes possible the bringing together of the study/teaching of the Portuguese language with the ideal of citizenship competencies. We postulate the importance of interdisciplinary pedagogical work in a context in which logic and rhetoric act in complementarity. The rhetorical perspective (PERELMAN, 1958 [1996], 1977 [1993], 1989 [1997]) supports the pedagogical work by means of the linguistic organization of text/discourse with the objective of structuring our points of view around how we interpret the world. The perspective of logic (PEIRCE, 1958) promotes an appreciation for argumentation, making explicit the bases of our discourse. This complementary relation between logic and rhetoric constitutes the theoretical foundation of our project, entitled "Respect for cultural diversity: the role of logic and rhetoric in the constitution of the 'I' citizen", which was approved by the MEC, as a Tutorial Education Program (PET) in the area of humanities and letters at the University for International Integration of the Afro-Brazilian Lusophony (UNILAB).
\end{abstract}

Keywords: discursive organization; rhetoric; logic.

\title{
1. INTRODUÇÃo
}

A educação escolar é um processo com nítida função política, haja vista os desdobramentos decisivos para o desenvolvimento das pessoas e da sociedade. Desde a publicação dos Parâmetros Curriculares Nacionais (MEC, 1998), privilegia-se a dimensão interacional e discursiva da língua e preceitua-se o domínio dessa língua como uma das condições para a participação plena do indivíduo em meio social (ANTUNES, 2003).

Nesse prisma, assume-se a discussão de como aproximar o estudo/ ensino da língua do ideal de competências para a cidadania, o que requer a formação de pessoas capazes de assumir a palavra, com criticidade e atuação construtiva. O conceito de "cidadania" aqui precisa ser claramente entendido em relação ao período histórico ao qual constituímos e por ele somos constituídos. Vivemos uma época marcada por interdependências internacionais, em que o saber gerenciar e superar conflitos, construindo normas negociadas de convivialidade, faz-se imprescindível ao exercício da 
cidadania (MOSCA, 2005). O confronto de diferentes pontos de vista, diversas visões de mundo, de tendências e de preferências faz-se notar em todas as esferas de atividade humana, o que requer, constantemente, embutir nossos pensamentos e crenças em argumentos que os justifiquem, de modo a que ofereçamos ao "outro" subsídios para que "aceite", "rejeite", "reformule", "comente" aquilo que acreditamos, e, quiçá, "colabore" com aquilo em que acreditamos, o que é necessário para que as pessoas coletivamente se reconheçam como membros de uma sociedade que constitui uma construção global, fruto da participação efetiva de seus múltiplos agentes.

Entendemos que a chamada competência retórica, aqui concebida como a capacidade de gerenciar questões éticas, estéticas e campos afins, passíveis de controvérsia, tornando viável a convivialidade, constitui um saber para além da competência comunicativa. No arcabouço teórico-metodológico da Linguística Funcionalista (NEVES, 1997), essa competência é, mais precisamente, entendida como concernente à capacidade humana de usar e interpretar expressões linguísticas de uma maneira interacionalmente satisfatória, o que implica a compreensão de expressões em uso e, por conseguinte, requer, envolve e pressupõe uma abordagem didática da sintaxe e da semântica à luz de uma perspectiva pragmática.

A fim de que se alcance o ideal de competência retórica, faz-se mister não apenas o desenvolvimento da competência comunicativa, a qual viabiliza, entre outras habilidades, a elaboração de construtos linguísticos que tenham como ponto de partida o acordo dos interactantes sobre premissas nas quais aquele que argumenta alicerça seu discurso e o conduz a conclusões autorizadas por justificativas, por técnicas argumentativas. Ora, a formação apenas retórica capacita indivíduos a "influenciar, por meio do discurso, a intensidade de adesão de um auditório a certas teses" (PERELMAN; TYTECA, [1958]1996, p. 16), o que é habilidade necessária. No entanto, se desejamos uma educação linguística para a cidadania, entendemos que é preciso ir além, é necessário pensar as bases de nossas conviç̧ões e repensar a adesão arbitrária e não justificada a afirmações ou crenças sobre o mundo. Esse é um trabalho concomitante à elaboração dos textos-discursos, e estamos convictos de que apenas assim podemos nos mostrar permanentemente abertos ao diálogo construtivo, expressão de uma sociedade plural, mas integral. Integral no sentido de um acordo compartilhado - incorporado na conduta - acerca daquilo que nos une (que nos faz igual) e, ao mesmo tempo, nos faz desejavelmente diferentes uns dos outros. É nesse prisma que a lógica, entendida aqui como ciência que se ocupa da constituição do pensamento, dialoga com a retórica, em relação de complementaridade, visando a um saber linguístico formador de cidadãos.

No afã, portanto, de aproximar o estudo/ensino da língua do ideal de competências para a cidadania, postulamos a produtividade de um tra- 
balho pedagógico no qual lógica e retórica atuam em paralelo. Enquanto a perspectiva retórica respalda o trabalho didático com a organização linguística do texto-discurso para fins de estruturação de nossos pontos de vista acerca de como interpretamos o mundo, a perspectiva da lógica viabiliza a introspecção para o que subjaz às teses defendidas, com vistas à discussão do por que rejeitamos o que rejeitamos, defendemos o que defendemos. Em relação de complementaridade, portanto, entendemos que o trabalho pedagógico que propomos é de desenvolvimento das habilidades de organização discursiva e de leitura reflexiva dos conteúdos discursivos que produzimos (ou reproduzimos) em nossos textos.

Ressaltamos que o trabalho com o estudo/ensino de língua aqui esboçado é, por sua própria natureza, multidisciplinar. O trabalho multidisciplinar (ou pluridisciplinar) implica estudo de dado objeto sob a perspectiva de duas ou mais disciplinas - cada disciplina trata o objeto de sua própria perspectiva, não há relação entre as disciplinas no que concerne à transposição de conceitos -, característica de um trabalho interdisciplinar. Assim "pluri" ou "multi" indica abundância de elementos homogêneos. O resultado é um estudo de um mesmo objeto (a construção textual-discursiva argumentativa, em nosso caso) sob olhares múltiplos e/ou distintos. Assinalamos que não se trata de ecletismo frouxo, mas da soma de disciplinaridades - no caso aqui a Lógica e a Nova Retórica - a fim de resolver problemas que estão colocados nas fronteiras das várias áreas do saber, os quais, em decorrência da disciplinaridade, foram deixados de lado. Compreendemos que um trabalho de estudo/ensino de língua restrito à construção argumentativa dá-se dentro de disciplinaridades como Retórica, Linguística de Texto e Linguística Funcionalista; mas um trabalho que transponha o domínio das técnicas de construção textual-discursiva da argumentação e permita a imersão no que subjaz axiologicamente à materialidade linguística está na fronteira das disciplinaridades, daí o diálogo que aqui propomos entre disciplinaridades.

Destacamos que o trabalho conjunto entre lógica e retórica visando à aproximação entre estudo/ensino da língua e ideal de competências para a cidadania, cuja fundamentação teórica é neste artigo apresentada, é a base da Proposta de Educação Tutorial (PET) intitulada "Respeito à diversidade cultural: o papel da lógica e da retórica na constituição do Eu cidadão". Trata-se de proposta de escopo multidisciplinar em Ciências Humanas elaborada por docentes (cujos principais proponentes são os autores do presente texto) da área de Humanidades e Letras da Universidade da Integração Internacional da Lusofonia Afro-Brasileira (UNILAB).

Tendo em vista que, historicamente, lógica e retórica são perspectivas entendidas como em oposição epistemológica, exporemos neste artigo o viéis que as permitem confluir para o êxito de um trabalho didático 
multidisciplinar com as línguas naturais, visando competências para a cidadania. Em primeira instância, reconstruímos, em linhas gerais, a história da retórica como arte oratória e o nascimento da ciência da lógica como seu contraponto. Na sequência, expomos como, a partir dos trabalhos de Perelman (1958 [1996], 1977 [1993], 1989 [1997]), proponente da Nova Retórica, o pensamento dialético reassume importância no âmbito das pesquisas sobre argumentação. Além disso, ilustramos a produtividade das técnicas argumentativas descritas nos trabalhos de Perelman e Tyteca, no que diz respeito à compreensão de categorias linguísticas em função discursiva, e como os trabalhos do filósofo Charles Peirce (1958) viabilizam uma investigação acerca do modo pelo qual o pensamento ocorre na mente humana e em linguagem natural, possibilitando trabalho reflexivo quanto aos pressupostos assumidos à revelia de reflexão na construção da argumentação.

\section{O DOMÍNIO DA ARGUMENTAÇÃO: DA DIMENSÃO DO PLAUSÍVEL À DIMENSÃO DO NECESSÁRIO}

Dos vários fins a que se presta a linguagem verbal, um deles é o persuasivo, ou seja, valemo-nos dela para efeito de fazer que outros aceitem nossos pontos de vista acerca de como interpretamos o mundo.

Registra-se que a habilidade de convencer como saber sistematizado surgiu, no século V a.C., com o nome de Retórica, na cidade da Sicília, na Grécia. Em seus primórdios, a Retórica tinha por objetivo instruir cidadãos comuns para fins de defesa de suas próprias causas. Da leitura de Reboul (1998), compreendemos que, por volta de 465, após a derrota dos povos que dominaram a Sicília, os cidadãos sicilianos encontraram-se despojados de suas terras. Tendo em vista a inexistência de quem pleiteasse suas causas, Corax e Tísias escreveram uma coletânea de preceitos práticos e fundaram escolas de ensino da arte retórica, visando habilitar os sicilianos a pleitear publicamente seus interesses. A Retórica foi o centro de todo o ensino durante dois mil e quinhentos anos. Tratava-se de uma disciplina textual, que objetivava ensinar as habilidades de falar em público de modo persuasivo. No âmbito da Retórica, a língua era concebida como um arsenal de estratégias discursivas para finalidades práticas, ou seja, para atender às necessidades oriundas do cotidiano.

Desde a Antiguidade, portanto, os gregos debruçaram-se sobre a "arte de falar", compreendendo que a arte de ter influência sobre outrem, por meio da linguagem verbal, não era apanágio da razão, pois o ser humano é feito de razão e paixão. Desde a Antiguidade, traçou-se distinção entre o 
que deriva da pura razão, postulando-se, assim, a necessidade de uma técnica demonstrativa capaz de "dizer a verdade", e o que deriva da interação dos espíritos, postulando-se, por sua vez, a necessidade de uma técnica expressiva suscetível de captar o interesse de um auditório, comovendo-o e conduzindo-o a uma ação intentada. Esta última constituiu o objeto da Retórica.

O deslocamento da Retórica de seu caráter prático deu-se a partir dos estudos realizados por Aristóteles. Este empreendeu análise do pensamento argumentativo formal, objetivando identificar modelos-padrão de argumentos, capazes de serem usados universalmente em qualquer contexto. o filósofo Aristóteles propôs dois modos básicos de raciocínio: por demonstração analítica e por raciocínio dialético.

o primeiro embasa-se numa relação entre proposições evidentes, que conduz o pensamento à conclusão verdadeira e em cuja base está apoiada a lógica formal. Na lógica formal, entendida como aquela em que as conclusões derivam necessariamente das premissas (em outras palavras: se as premissas são verdadeiras, e o argumento conta com uma forma lógica válida, então a conclusão não pode, necessariamente, deixar de ser, também, verdadeira), a demonstração das relações entre as premissas e a conclusão é suficiente para impor uma afirmação entendida como verdadeira. Na demonstração analítica, portanto, a personalidade do emissor é indiferente à validade de uma demonstração e o alcance desta validade é universal.

o segundo tipo de raciocínio, por sua vez, manifesta-se por meio de um argumento sobre enunciados prováveis, que viabilizam conclusões apenas verossímeis. Neste segundo modo de raciocínio, a criação de estratégias de convencimento faz-se imprescindível, dado que não há uma ligação necessária entre as premissas e a conclusão. No raciocínio dialético, a personalidade do emissor é essencial à aceitação de uma dada conclusão - daí a preocupação das agências de marketing comercial ou político na construção de uma "imagem" convincente do emissor - e o alcance dessa aceitação restringe-se a auditórios específicos.

Com o pensamento moderno, o interesse pelo raciocínio dialético, forma de raciocínio característica da argumentação retórica, diminuiu. Segundo Perelman e Tyteca ([1958] 1996), a partir de Descartes, deu-se a valorização, na argumentação, do que é necessário, em oposição ao domínio do plausível, do verossímil, do provável. Descartes elabora um sistema de proposições necessárias, as quais se impõem a todos os humanos. Para Descartes, a evidência é a sustentação do pensamento racional; o desacordo é, portanto, sinal de erro.

Este realce à evidência como sustentação do pensamento racional, bem como a noção de necessidade, serão questionados nos trabalhos 
de Perelman (1958 [1996], 1977 [1993], 1989 [1997]), os quais retomam a Retórica dos gregos e romanos e recolocam o raciocínio dialético no bojo das pesquisas sobre argumentação. Essa é entendida por ele não como o espaço da "desrazão", mas como "o discurso do método de uma racionalidade que já não pode evitar os debates e deve, portanto, tratá-los e analisar os argumentos que governam as decisões." (PERELMAN; TYTECA, [1958]1996: XX). Consideramos essa releitura da retórica na seção subsequente.

\section{O DOMÍNIO DA ARGUMENTAÇÃO: NOVAMENTE, À DIMENSÃO DO PLAUSÍVEL}

o discurso argumentativo (modo de discurso aparentado com o dialético, pois seus raciocínios partem de premissas prováveis e verossímeis) é entendido, em termos retóricos, como um construto linguístico que tem como ponto de partida o acordo do auditório sobre certas premissas (convicções comumente admitidas, hábitos e/ou crenças coletivas de um grupo de agentes), nas quais aquele que argumenta alicerça seu discurso e conduz a conclusões autorizadas por justificativas (por regras de inferências e outras técnicas argumentativas). Essa concepção de argumentação não foi, como mencionamos, objeto de interesse por várias décadas. É a partir dos trabalhos de Toulmin e Perelman ${ }^{1}$, na segunda metade do século XX, que ocorre o resgate da importância do raciocínio dialético. Com estes, os olhares dos pesquisadores voltam-se para como opiniões são justificadas e refutadas na vida em sociedade. $O$ problema básico da retórica aristotélica volta ao centro das atenções: "quais são os mecanismos, ou seja, as estruturas lógicas que sustentam as formas dos discursos (das mensagens) que visam persuadir?" (REALE, 2007, p.169).

Enquanto Toulmin formulou um instrumento analítico para o estudo da argumentação, Perelman e Tyteca formularam uma descrição das técnicas argumentativas (ou esquemas argumentativos) utilizadas pelas pessoas a fim de ganhar a aprovação de outras para seus pontos de vista.

Como estudo dos argumentos que governam as decisões, a Nova Retórica compreende que as formas verbais da argumentação somente podem ser entendidas como tais na prática do discurso, uma vez que elas servem a fins comunicativos. Nas palavras dos próprios autores temos: "Recusamos separar, no discurso, a forma do fundo ${ }^{2}$, estudar as estruturas e as figuras

1 Em 1958, foram publicadas as obras The Uses of Argument, de Stephen Toulmin, e La nouvelle rhétorique: traité de l'argumentation, de Chaïm Perelman e Lucie Olbrechts-Tyteca.

2 Perelman e Tyteca, nesse contexto, referem-se à "forma" como a técnica da apresentação dos elementos nos quais o orador deseja centralizar a atenção em seu discurso. Os autores criticam 
de estilo independentemente da meta que devem cumprir na argumentação." (PERELMAN; TYTECA, [1958] 1996, p.161,162).

A terceira parte da obra Tratado da Argumentação: A Nova Retórica é dedicada à compreensão de esquemas de argumentos, os quais se caracterizam por processos de ligação e de dissociação. Os esquemas que aproximam elementos distintos e permitem estabelecer entre eles uma solidariedade que visa, seja estruturá-los, seja valorizá-los de modo positivo ou negativo um pelo outro são compreendidos como processos de ligação. Por sua vez, os esquemas que separam elementos considerados em um todo, ou pelo menos um conjunto solidário dentro de um mesmo sistema de pensamento, são compreendidos como processos de dissociação.

Acerca da importância dos esquemas de argumentos, descritos por Perelman e Tyteca, lemos, em Mosca (2005, p.6), o seguinte:

A sistematização para o estudo destes [dos lugares-comuns, que fornecem material que fundamentará as provas, contra-provas, os modelos, a voz de autoridade e os recursos para o exercício dos mais variados tipos de argumentos] nos vem de Perelman \& Tyteca, ao classificá-los em argumentos de dissociação e argumentos de ligação, compreendendo estes últimos os argumentos quase lógicos, os argumentos que se baseiam no real e os argumentos que fundamentam o real. Sua pormenorizada descrição procura dar conta dos mecanismos presentes na atividade argumentativa dos interlocutores que a efetuam nas mais diversas situações do cotidiano e não apenas naquelas mais formais e elaboradas em que são convocados a se pronunciar.

Os argumentos quase-lógicos tiram sua força persuasiva da proximidade que mantêm com os modelos de raciocínios formais, lógicos ou matemáticos; eles têm, portanto, uma aparência demonstrativa. Por exemplo, a acusação de cometer uma falta de lógica é, em geral, uma argumentação quase-lógica, pois aquele que assim acusa prevalece-se do prestígio do raciocínio rigoroso. Tal acusação tanto pode ser precisa, situando-se no próprio plano da argumentação - casos em que há acusação de incompatibilidades - como genérica - casos em que há a acusação de estar-se proferindo um discurso passional, em contraposição a um discurso lógico. Nestes casos, o ouvinte contrapõe o discurso ouvido à imagem de um discurso que lhe pa-

a ênfase que muitos estudiosos concernem a essas técnicas, a ponto de estudá-las sem correlacionálas às metas que essas formas devem cumprir na argumentação, procedimento este que, segundo os autores, deu origem à esterilidade da retórica. Assim, insurgindo-se contra essa redução da retórica à técnica da apresentação, os autores afirmam que se recusarão a separar a forma (as técnicas de apresentação) do fundo (os propósitos comunicativos aos quais a técnica se presta). 
rece superior, que seria composto de esquemas lógicos. São argumentações caracterizadas pela presença de argumentos quase-lógicos as seguintes: pela apresentação de incompatibilidades; pelo ridículo; pela definição; pela tautologia; pela regra de justiça; pelo recurso às relações recíprocas; pelo recurso à transitividade; pela inclusão da parte no todo; pela divisão do todo em suas partes; pela comparação; pelo sacrifício; pelo recurso às probabilidades.

Os argumentos fundamentados na estrutura do real concernem aos modos de raciocínio pelos quais se apresentam opiniões quanto ao que se considera real. Os proponentes da Nova Retórica subdividem esses argumentos em conformidade às estruturas do real aos quais se aplicam. Assim, há argumentos que se aplicam a ligações de sucessão, que unem, portanto, um fenômeno às suas consequências ou às suas causas; e os que se aplicam às ligações de coexistência, que unem uma pessoa a seus atos, um grupo aos indivíduos que dele fazem parte, uma essência a suas manifestações. São estruturas argumentativas caracterizadas pela presença de argumentos fundados na estrutura do real que se aplicam às relações de sucessão: pelo recurso ao vínculo causal; pelo recurso ao argumento pragmático; pelo recurso ao vínculo causal como relação de um fato com sua consequência ou de um meio com um fim; pela ênfase nos fins e nos meios; pelo recurso ao argumento do desperdício; pelo recurso ao argumento da direção; pelo recurso à superação. Por sua vez, são argumentações caracterizadas pela presença de argumentos fundados na estrutura do real que se aplicam às ligações de coexistência: argumentação pelo recurso à interação entre atos e pessoa ${ }^{3}$; argumentação pelo recurso ao argumento de autoridade.

Os argumentos que arregimentam ligações que fundamentam a estrutura do real recorrem a dois tipos básicos de fundamento: pelo caso particular e por analogia. São argumentações caracterizadas pela presença de argumentos que recorrem ao caso particular: argumentação pelo recurso ao exemplo; argumentação pelo recurso à ilustração; argumentação pelo recurso ao modelo e ao antimodelo; argumentação pelo recurso à analogia.

Visando à compreensão da técnica da dissociação de noções e à apreciação de seus resultados, os proponentes da Nova Retórica examinam

3 Acerca da noção de "pessoa", é necessário destacá-la como o fazem os proponentes da Nova Retórica, a fim de que não se transmita uma ideia errônea, que nos levaria a associar as relações entre uma pessoa e seus atos como necessária, tornando essas relações semelhantes às existentes entre os objetos e suas propriedades, o que seria negar a plasticidade humana e ir de encontro a um discurso em razão de ser de interlocutores situados sócio-historicamente. Assim, destacam Perelman e Tyteca que "a concepção de pessoa pode variar muito conforme as épocas e conforme a metafísica adotada." (PERELMAN; TYTECA, [1958]1996, p.334). Desta feita, "Na argumentação, a pessoa considerada suporte de uma série de qualidades, autora de uma série de atos e de juízos, objeto de uma série de apreciações, é um ser duradouro a cuja volta se agrupa toda uma série de fenômenos aos quais ela dá coesão e significado. Mas, como sujeito livre, a pessoa possui essa espontaneidade, esse poder de mudar e de se transformar, essa possibilidade de ser persuadida e de resistir à persuasão, [...]" (PERELMAN; TYTECA, [1958]1996, p.336 - grifo nosso). 
a dissociação das noções que originam o par "aparência-realidade", considerado o protótipo de toda dissociação nocional em decorrência de seu uso generalizado, e a dissociação das noções que originam vários outros pares filosóficos (meio-fim, ato-pessoa, individual-universal etc).

Para efeito de ilustração da aplicabilidade de tais técnicas na compreensão do modo de discurso argumentativo, destacamos o trabalho empreendido por Menezes (2012) em seu estudo sobre as expressões linguísticas modalizadoras deônticas (instauradoras de obrigações, permissões e proibições) na construção da argumentação sob viéis retórico.

\subsection{EXEMPLO DA PRODUTIVIDADE DA RETÓRICA PERELMANIANA NA COMPREENSÃo DA CONSTRUÇÃo LINGUíSTICA DA ARGUMENTAÇÃo.}

Analisemos a propaganda do Seguro Itaú Vida.

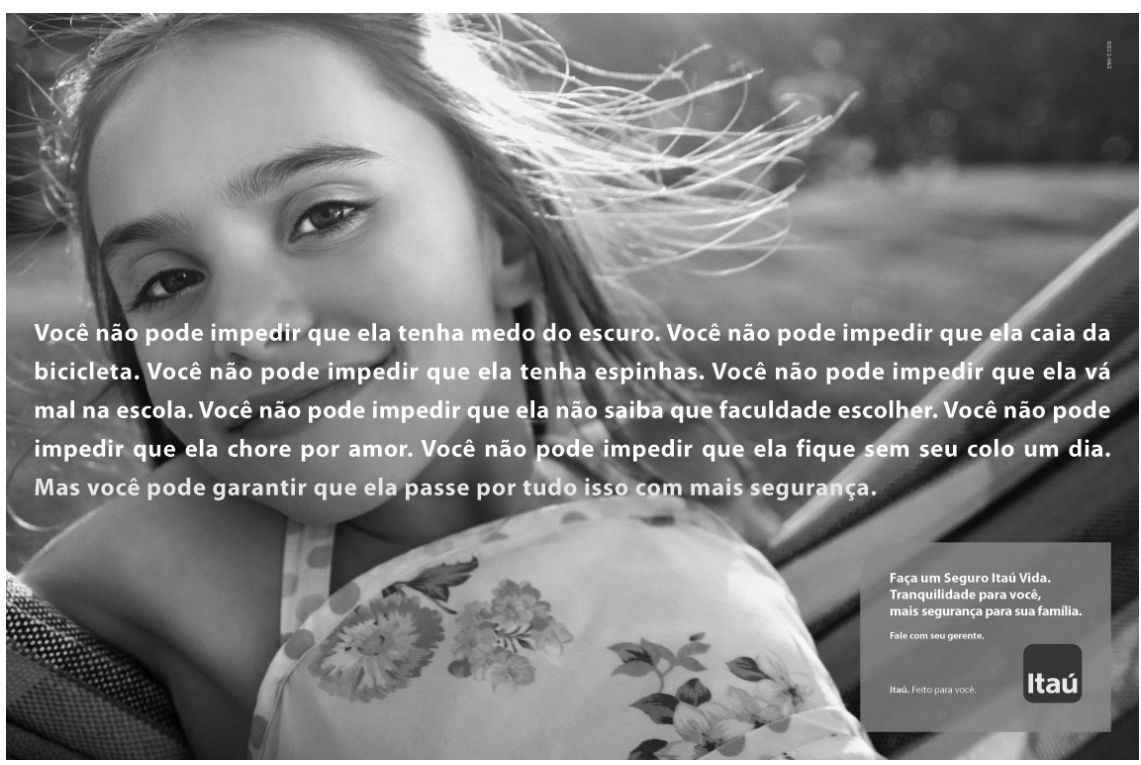

No texto em apreciação, inicialmente, o público alvo - indivíduos responsáveis pela criação de uma criança - é confrontado com uma realidade que, em geral, procuram esquecer - há fatos imprevistos ou fortuitos que escapam ao controle humano. Assim, os adultos que têm uma criança sob sua guarda não podem impedir uma série de eventos que gostariam de impedir: que sua criança tenha medo do escuro, que ela caia da bicicleta, que ela tenha espinha, que ela vá mal na escola, que ela não saiba que faculdade escolher, que ela chore por amor, que ela fique sem seu colo um dia. Observamos que as constatações de impotência concernem às várias 
etapas da vida: da infância (quando cair de bicicleta é comum), passando pela adolescência (quando ter espinhas é corriqueiro), até chegar o momento em que os responsáveis se vão e as outrora crianças - às vezes, ainda crianças - prosseguirão, sem eles.

Linguisticamente, temos uma série de expressões da modalidade chamada de dinâmica, ou seja, de um subtipo modal por meio do qual falantes/escritores podem descrever a habilidade de outrem ou de si mesmo e envolver-se em evento designado no enunciado. As expressões modalizadoras dinâmicas concernem às capacidades intrínsecas ou adquiridas. Destacam Hengeveld e Mackenzie (2008) que, em algumas línguas, traça-se distinção entre habilidade intrínseca (estar habilitado para) e adquirida (saber como). No contexto em apreciação, têm-se inabilidades intrínsecas - não estar habilitado a, em decorrência da própria constituição (ou condição) humana.

Após trazer à tona inabilidades intrínsecas, o texto mostra que há uma permissão deôntica alentadora: você pode garantir que ela (sua criança) passe por tudo isso com mais segurança. A fonte dessa permissão é o Banco Itaú. Por meio da aquisição do Seguro Itaú Vida, você não é obrigado, mas pode conceder mais segurança para sua família. No canto direito, em quadro que se sobressai pelo tom laranja mais vívido, temos duas expressões modalizadoras deônticas com verbos no imperativo: "Faça um seguro Itaú Vida", "Fale com seu gerente". A fonte deôntica é o Banco Itaú, e o alvo são adultos responsáveis por uma criança. Entre um e outro comando, temos o argumento pragmático (por meio do qual é possível apreciar um ato ou um acontecimento de acordo com as consequências práticas - favoráveis ou desfavoráveis -resultantes): "Tranquilidade para você, mais segurança para sua família".

Assim, em termos de construto argumentativo, o texto inicia-se com sete expressões linguísticas da modalidade dinâmica - as quais visam desestabilizar emocionalmente o público alvo, pois eles são (re)lembrados de sua incapacidade existencial (fruto da condição humana inserida em um universo em que há espaço ontológico para eventos provenientes do acaso). Esse efeito desestabilizador torna o público alvo mais propenso a ler a oferta do seguro como um alento. Na sequência, eis o alento: há um meio de remediar essa incapacidade - o Itaú permite a você a aquisição de um seguro para sua família em caso de você vir a faltar-lhe. Como conclusão, basta ao público alvo atender aos comandos: fazer um Seguro Itaú Vida; para tanto, é preciso falar com seu gerente. $O$ alicerce dessa argumentação é o argumento pragmático - "tranquilidade" e "segurança" são metas de vida.

Postulamos a relevância de um trabalho didático de leitura-construção de textos-discursos argumentativos a partir do reconhecimento e manuseio consciente dos esquemas de argumentos descritos no Tratado. 
Entendemos que o manuseio dessas técnicas é parte da competência comunicativa a ser desenvolvida na escola, é parte do processo de letramento.

No entanto, como já apontamos, para um ensino de língua como ideal de competência para a cidadania é preciso um trabalho para além da leitura-construção textual-discursiva. Entende-se que argumentar, quer seja à luz de argumentos analíticos, dedutivos e/ou formais, quer seja em conformidade como uma argumentação de matiz dialético, constitui conduta que expressa respeito ao outro, e condição de possibilidade de uma sociedade plural, na qual os agentes, provenientes de múltiplas tradições culturais, possam encontrar espaços efetivos de interação habitual e linguística, com base no diálogo aberto, e distantes de pontos de vistas tenazes (desprovidos de flexibilidade para mudança), dogmáticos e/ou autoritários. É o que, apoiados na filosofia de Charles Sanders Peirce (1958), exploraremos na próxima seção.

\section{A ADESÃo OU FIXAÇÃo DAS CRENÇAS: O CONJUNTO DOS HÁBITOS QUE CONSTROEM A TESSITURA ARGUMENTATIVA}

Grande parte dos acadêmicos de hoje caracteriza a lógica como um ramo do conhecimento fundamentalmente teórico, que se dedica apenas ao estudo de formas lógicas embutidas em uma linguagem abstrata, e não, de modo mais amplo, como uma investigação sobre o processo de pensamento, do modo pelo qual o pensamento ocorre na mente e em linguagem natural. Distantes de tal concepção, enfatizamos a relevância da lógica também no que diz respeito à apreciação dos argumentos em linguagem natural e $o$ papel normativo que tal ciência pode desempenhar na construção de uma sociedade multicultural e solidária. Embutir nossos pensamentos e crenças em argumentos constitui um exercício de cuidado com o "outro", com aquele que interagimos, uma vez que estamos oferecendo a ele as razões que sustentam nossas crenças. Estamos oferecendo subsídios para que o outro, nosso parceiro, "aceite", "rejeite", "reformule", "comente", "colabore" com aquilo que acreditamos, o que é necessário para que possamos construir um espaço solidário efetivo, e para que possamos coletivamente nos reconhecer como membros de uma sociedade cooperativa, fruto da participação efetiva de seus múltiplos agentes.

À luz de seu ideal normativo (ou ético), a lógica (que é parte da metodologia filosófico-científica) pode ser concebida como o estudo dos modos válidos ou corretos de pensar, raciocinar, argumentar, inferir. De modo mais explícito, a lógica constitui uma ciência que se ocupa de como 
o pensamento deve ser, para que o pensamento, expresso em argumentos, esteja em acerto consigo mesmo e com o mundo. Já o argumento pode ser caracterizado como um conjunto de premissas (afirmações sobre estados de coisas) e conclusão. É esperado que premissas e conclusão estejam relacionadas de modo tal que, se as premissas são verdadeiras, então a conclusão não pode deixar de ser igualmente verdadeira. A conclusão constitui, pois, no caso de o argumento ser válido, consequência lógica das premissas. Ou, em outras palavras, a conclusão se segue logicamente das premissas, e as premissas constituem uma boa razão para a aceitação da conclusão. O que garante essa relação, ou conexão, desejável entre premissa e conclusão é, justamente, a forma lógica do argumento, ou aquilo que faz com que, de premissas verdadeiras, possamos extrair uma conclusão verdadeira. Vale destacar, contudo, que, em um espaço plural, diverso e multicultural, aquilo que é, digamos, considerado uma premissa verdadeira (ou uma hipótese de conduta viável) para um grupo de agentes, pode ser, por outro lado, considerado falso (ou como uma hipótese de conduta não-viável) por outro. Isso é desejável, e constitui condição necessária à existência de distintas perspectivas epistemológicas e habituais.

O que não deveria acontecer, em respeito à multiplicidade encontrada nos espaços plurais, é a adesão arbitrária e não justificada a afirmações ou crenças sobre o mundo. Asserções do tipo: "acredito na veracidade da afirmação ou proposição $X$ (ou na adequabilidade da linha de ação $Y$ ) porque $\mathrm{X}$ (ou a linha de ação Y) parece desejável e agradável. Além disso, nunca em minha comunidade a afirmação X (ou a linha de ação Y) foi contestada e, portanto, não estou interessado em refletir sobre aquilo que justifica minha crença em X (ou na adequabilidade da linha de ação Y) nem oferecer razões para que vocês possam aceitar X como verdadeira ou mesmo plausível ou Y como uma linha de ação adequada". Em uma sociedade plural, sensível às distintas perspectivas culturalmente diversas, é sempre necessário, e altamente desejável, que nossas afirmações estejam fundamentadas em argumentos, para que sejamos capazes, no diálogo com o outro, de explicitar nossas razões para acreditar na veracidade (relevância, plausibilidade) daquilo que julgamos ser o caso. Apenas assim podemos nos mostrar permanentemente abertos ao diálogo construtivo, colaborativo, expressão de um espaço plural e integral.

Em A Fixação das Crenças, o filósofo Charles Sanders Peirce (1958) propõe os métodos pelos quais nos fixamos ou aderimos à veracidade das afirmações, proposições ou crenças. Um pressuposto fundamental deste texto é que um agente A pode, da crença na veracidade de uma afirmação ou proposição $P$, derivar um conjunto de hábitos de ação capazes de remover a irritação de uma dúvida (dúvida que paralisa a ação e impede o conhe- 
cimento). Vale aqui destacar que uma proposição constitui uma afirmação que fazemos sobre a realidade, e a proposição pode, pois, ser analisada em termos de verdadeiro ou falso. A proposição constitui, por assim dizer, um quadro, ou pintura, da realidade: se o quadro retratado pela proposição, a afirmação que a proposição faz acerca da realidade, corresponde aos fatos, está em conformidade com a própria realidade, então a proposição assume valor lógico "verdadeiro"; caso contrário, a proposição assume valor lógico "falso". Assim, por exemplo, a proposição "Está chovendo" assume valor lógico "verdadeiro" (é verdadeira) se, e somente se, olhamos pela janela e verificamos que, de fato, a chuva cai lá fora (na própria realidade). Neste caso, o conteúdo proposicional, o componente linguístico da proposição, o que a proposição afirma ser o caso, está em concordância com a própria realidade. O ponto que particularmente nos interessa é que, se acreditamos que uma proposição é verdadeira, então podemos dela derivar hábitos de ação e, desse modo, moldar nossa conduta no mundo. Caso acreditemos, digamos exemplarmente, na veracidade (adequabilidade e/ou razoabilidade) da proposição "Toda modalidade de censura ou de não-liberdade de expressão é moral elou politicamente condenável", tenderemos, caso venhamos a nos deparar com alguma modalidade de censura e/ou comprometimento da liberdade, a imediatamente agir no mundo de modo a evocar valores democráticos, e argumentar em defesa da restauração da nossa expressão, ou voz, individual no contexto do todo coletivo ou social mais amplo; essa imediatidade para argumentar em defesa daquilo que acreditamos, em circunstâncias específicas, constitui um hábito de conduta ou ação - ação linguística, em especial. Por outro lado, sob a influência da dúvida, o agente tende a reestruturar seu conjunto de crenças, no interior do qual a dúvida produz uma irritação. A dúvida em geral dispara o processo de pensamento, sendo o papel fundamental do pensamento a produção de um hábito de conduta, comportamento ou ação.

Mais explicitamente, e para Peirce, o agente pode se fixar às crenças sem suficiente justificativa racional para tanto. Ele tende a aplicar os hábitos derivados das suas crenças sem hesitar. Aprende a "olhar com desprezo" para tudo aquilo que se contrapõe a seus hábitos, que são, na maior parte, mantidos sem substituição, ou formação, de novos. Esse apego irrefletido e tenaz aos hábitos conduz conforto e tranquilidade mental, e isso, segundo Peirce (1958), compensa as inconveniências advindas do apego (às vezes enganador) às concepções subjacentes aos hábitos assim mantidos. Destaquemos que a experiência da dúvida produz um sentimento de desconforto tal, que procuramos investigar até que ela seja eliminada, e uma nova crença, na condição de um sentimento confortante, seja estabelecida. O agente, mantendo seus hábitos dessa maneira, pode viver se afastando de 
virtualmente tudo o que venha a sugerir alterações em suas crenças. Peirce chamou esse método de fixação da crença de o "método da tenacidade".

0 agente pode se fixar às crenças de certa instituição à qual pertence. O papel da instituição é zelar pela aceitação, pelos membros, dos comportamentos derivados do seu (da instituição) conjunto de crenças, estabelecendo critérios para colocar, de um lado, os comportamentos considerados apropriados e desejáveis e, de outro, aqueles comportamentos considerados inapropriados e indesejáveis. O conjunto de crenças (da instituição) é constantemente reafirmado pela educação dos novos membros. A instituição, diretamente dependendo de seu poder, pode tentar evitar, em maior ou menor grau, que crenças e condutas contrárias às por ela legitimadas sejam ensinadas, defendidas e expressas. Pode ser que haja alteração no conjunto de crenças de certa instituição no transcurso do tempo. Contudo, sugere Peirce, as alterações no âmbito das instituições são em geral tão lentas que, durante a vida do indivíduo, elas seriam imperceptíveis e, por isso, as crenças individuais permaneceriam essencialmente fixadas. Peirce chamou esse método de fixação das crenças de o "método da autoridade".

$\mathrm{O}$ agente pode se fixar às crenças por elas serem, ou parecerem, "agradáveis à razão". Certo ideal estético, envolvido ou pressuposto na noção de "agradável", estaria presente neste método de fixação das crenças. Tratar-se-ia, antes de qualquer outra coisa, de se fixar a crença via "mera questão de gosto". A fixação da crença não estaria ancorada na experiência, mas, antes, "naquilo que estaríamos prontos a acreditar" e, novamente, em nossas preferências individuais. Peirce chamou esse método de fixação das crenças de "método a priori".

$\mathrm{O}$ agente pode se fixar às crenças de modo provisório, e/ou passível de alteração, além de manifestar disposição para justificar, com argumentos, suas crenças (ou afirmações) quando requerido e, além disso, abandonar parte de suas crenças (ou afirmações) no caso de elas se mostrarem em discordância com a experiência. Peirce caracteriza a experiência como o "[...] curso da vida". Em caso de uma discordância entre crença e experiência, o indivíduo, conduzido por esse método de fixação da crença, tenderá a admitir e vivenciar uma dúvida real acerca disso (da discordância crença/experiência), e a crença deixará (tenderá a deixar) de constituir uma crença. Para que possamos aplacar dúvidas experienciadas de modo satisfatório e estável, devemos estar apoiados em coisas que não tenham suas razões de ser dadas por algo de natureza meramente individual e/ou subjetiva. Devemos (segundo Peirce) estar apoiados "[...] em alguma permanência externa", em "[...] alguma coisa sobre a qual o pensamento não possua efeito ["desconfigurador"]", a saber, a realidade.

Da leitura de Peirce, compreendemos que o estudioso caracteriza a verdade como uma correspondência entre o conteúdo de uma proposição 
$P$ e essa "permanência externa" ou realidade como um fato (ou conjunto de fatos) $F$. Mais explicitamente, a verdade teria, assim, uma dimensão fundamentalmente pública, em virtude de ela constituir uma concordância entre uma proposição (ou um conjunto de proposições) e aquilo que a comunidade de investigadores (a comunidade filosófica e científica) tende a convergir caso persista suficientemente na investigação. Esse "limite" que atrairia as mentes dos investigadores seria a realidade. O método de fixação da crença acima esboçado - por Peirce chamado de método filosófico-científico - tem por hipótese fundamental a existência de: "[...] coisas reais, cujas propriedades são inteiramente independentes de nossas opiniões acerca delas; essas coisas reais afetam nossos sentidos de acordo com leis regulares [...]". "[...] podemos verificar pelo raciocínio como as coisas realmente são e, qualquer homem, se possuir suficiente experiência e raciocinar [...], será conduzido à conclusão verdadeira". (CP, 5.384). Notemos, em particular, que os investigadores (os cientistas) são conduzidos à realidade pela experiência, eles não criariam (pelo conhecimento) a realidade, há uma independência da realidade em relação à comunidade de investigadores, ainda que os seus (da realidade) limites sejam expressos (sempre de modo parcial e provisório) em proposições, ou teorias científicas, derivadas da prática coletiva da produção da ciência.

Ainda que os quatros métodos - tenacidade, autoridade, a priori e filosófico-científico - possam, a partir da fixação da crença, remover a irritação da dúvida, o método filosófico-científico é, de acordo com Peirce, o que produz as mais confiáveis respostas a tal irritação, uma vez que, no futuro estendido, as crenças filosófica e cientificamente fixadas terão uma probabilidade maior de serem "verdadeiras". Mas, em um espaço solidário, multicultural e diverso, não pode haver "verdades absolutas", verdades independentes das construções coletivas (hábitos/costumes, dimensões afetivas e assim por diante) que, em conjunto, caracterizam uma sociedade. Sendo assim, a parte "científica", do método filosófico-científico, tem, por assim dizer, "peso menor" no diálogo intercultural, voltado para a construção do apreço à diversidade e à cooperação solidária em diversos âmbitos da vida. Já a importância da parte "filosófica", do método filosófico-científico, para a construção de uma sociedade efetivamente plural e solidária, permanece fundamental: sem a disposição para, quando requerido pelos nossos parceiros, explicitar e deixar claro, com base em argumentos, as razões para a nossa aceitação de uma proposição, afirmação, crença ou curso de ação, não parece haver qualquer base para construção coletiva de uma sociedade plural e solidária, em oposição a uma sociedade "tenaz, a priori e autoritária". 


\section{Considerações FinAIS}

Procurou-se apontar que as competências para o exercício da cidadania parecem requerer, ao mesmo tempo, e de modo complementar, (i) uma formação retórica (capaz de habilitar os indivíduos a influenciar, discursivamente, a adesão de um auditório, e/ou grupo de agentes, a certas crenças, proposições, hipóteses, conclusões e assim por diante) e (ii) uma formação lógica, aqui concebida como disposição para argumentar, com o auxílio das formas lógicas válidas, em defesa daquilo que julgamos ser o caso, acreditamos, desejamos e assim por diante. A proposta de pesquisa, elaborada por docentes da Área de Humanidades e Letras da UNILAB, do grupo PET "Respeito à diversidade cultural: o papel da lógica e da retórica na constituição do Eu cidadão", alicerça-se na complementaridade fundamental entre retórica e lógica, esboçada e explicitada acima e nas seções anteriores.

Entende-se que as práticas argumentativas criam facilidades para a interação entre os grupos sociais. $O$ apreço pelos argumentos e a permeabilidade ao discurso do "outro" favorecem a convivência entre as diferentes culturas, e tem por condição de possibilidade o respeito mútuo e a valorização da diversidade. Por extensão, favorecem, também, não apenas a produção de conhecimento, mas, igualmente, o processo de ensino-aprendizagem. Saber defender pontos de vista a partir do manuseio consciente de técnicas argumentativas e saber ler criticamente os valores axiológicos que subjazem aos construtos argumentativos que produzimos e os que nos atingem cotidianamente são capacidades que tornam a cidadania exercível de fato. E o desenvolvimento dessas capacidades deve ser meta dos vários níveis de ensino: da educação fundamental à superior.

Neste sentido, nossa proposta é de desenvolvimento de um arcabouço teórico-metodológico viabilizador de um estudo/ensino da língua portuguesa a partir da interlocução entre retórica e lógica, visando à formação do cidadão.

\section{REFERÊNCIAS}

ANTUNES, I. Aula de português: encontro \& interação. São Paulo: Parábola Editorial, 2003.

HENGEVELD, K.; MACKENZIE, J. L. Functional discourse grammar: a typologically based theory of language structure. Oxford: Oxford University Press, 2008.

MARES, E. D. Relevant logic: a philosophical interpretation. Cambridge: Cambridge University Press, 2004. 
MENEZES, L. C. DE; ANDRADE, R. S. C. DE. LóGICA E RETóRICA EM DIÁLOGo: POR UM ESTUdo/ENSINO...

MENEZES, L. C. de. Modalização deôntica e retórica perelmaniana. Revista do Programa de Pós-Graduação em Letras da Universidade de Passo Fundo, Passo Fundo, v.8, n.2, p.162-176, jul./dez. 2012.

MINISTÉRIO DA EDUCAÇÃO E CULTURA. Parâmetros Curriculares Nacionais: terceiro e quarto ciclos do ensino fundamental - língua portuguesa. Secretaria da Educação Fundamental. Brasília: MEC/SEF, 1998.

MOSCA, L. do L. S. A atualidade da retórica e seus estudos: encontros e desencontros. In: RETóRICA. CONGRESSO VIRTUAL DO DEPARTAMENTO DE LITERATURAS ROMÂNICAS, I, 2005. Atas... Disponível em <http://www.fflch.usp.br/dlcv/lport/pdf/linei002.pdf>. Acesso em 23/1/2014.

NEVES, M.H.M. A gramática funcional. São Paulo: Martins Fontes, 1997.

PEIRCE, C. S. Collected Papers -8 vol. Org. HARTTSHORNE, C; WEISS, Cambridge, Ma: Harvard University Press, 1958.

PERELMAN, C.; OLBRECHTS-TYTECA, L. Tratado da argumentação: a nova retórica. Trad. de Maria Ermantina Galvão Pereira. São Paulo: Martins Fontes, 1996. (Trad. de Traité de l'Argumentation. La Nouvelle Rhétorique. Paris: PUF, 1958).

O Império Retórico: retórica e argumentação. Porto: Ed. ASA, 1993 (trad. de L'Empire Rhétorique, Paris: Ed. Vrin, 1977).

. Retóricas. São Paulo: Martins Fontes, 1997 (trad. de Rhétoriques. Bruxelles: Ed. de l'Université de Bruxelles, 1989).

REALE, Giovanni. História da filosofia grega e romana IV: Aristóteles. São Paulo: Edições Loyola, 2007.

REBOUL, O. Introdução à retórica. Trad. Ivone Benedetti. São Paulo: Martins Fontes, 1998.

TOUMIN, S. E. Os usos do argumento. Tradução Reinaldo Guarani. São Paulo: Martins Fontes, 2006.

Submetido em: 20/03/2013

Aceito em: 18/10/2013 